\title{
VEGETABLE LIPIDS AS COMPONENTS OF FUNCTIONAL FOODS
}

\author{
Milan Stuchlík, Stanislav Žák
}

Research., Development and Clinical Department, IVAX-CR a. s.,Ostravská 29, 74770 Opava 9, Czech Republic, e-mail:milan_stuchlik@ivax-cr.com

Received: September 19, 2002

Key words: $\quad$ Lipids / Vegetable oils / Fatty acids / Fatty alcohols / Isoprenoids / Phytosterols / Tocopherols / Tocotrienols / Policosanols

Nutritionally beneficial compounds naturally present in vegetable lipids will be subject of this minireview. This article will discuss lipidic compounds from less known vegetable sources and potential advantages of its incorporation into human diet as a functional ingredient.

\section{INTRODUCTION}

Functional foods are defined as having disease preventing and/or health promoting benefits in addition to their nutritive or processing value. The primary role of diet is to provide sufficient nutritients to meet metabolic requirements of an individual and to give a consumer a feeling of satisfaction and well-being through hedonistic attributes such as taste.In fact, diet can not only help to achieve optimal health and development, but it might also play an important role in reducing the risk of disease. In present society the concepts in nutrition change and the following trends are of particular importance:

increase of the number of elderly people,

desire for improved quality of life,

increasing health care costs and increasing cost of days lost from work,

continuing increase in life expectancy.

A food can be regarded as "functional" if it is satisfactorily demonstrated to affect beneficially one or more target functions in a body, beyond adequate nutritional effects. Functional food can be a natural food, a food to which a component has been added, or a food from which a component has been removed by technological or biotechnological process.

Functional foods must be safe according to all standards assessing food risk. However, the concept of risk versus benefit can not be applied in such a straightforward manner as it is for drugs. Finally, long term consequences of interactions between functional food components and functions in a body and interactions between components must be carefully monitored ${ }^{1}$. The major problems associated with functional foods concern intake and effect. In order to determine that a food has an effect beyond its nutritional attributes it is necessary to confirm that the target population is exposed to the food which contains putative active agent and that this particular component possesses a desired effect. Since the diet of most adults is complex and varied, the correlation between distinct effects and specific dietary constituents is difficult to confirm in free-living individuals ${ }^{2}$.

\section{VEGETABLE FATS AND FATTY ACIDS}

Vegetable seeds are an original source of fats and fat-soluble vitamins, both important in human diet. Certain vegetable fats, solid at room temperature, are called butters. Most natural vegetable oils contain a part of saturated fatty acids with even number of carbon atoms (in its triacylglycerol structure) and a part of unsaturated fatty acids with isolated double bounds, particularly in cis-configuration. Some trans- fatty acids are also known to occur naturally, e.g.within oils of some genera of the Compositae plant family ${ }^{3}$. Fatty acid parts of triacylglycerols convert into their geometrical and positional isomers due to operating conditions at various processes such as refining, deodorization and hydrogenation. Formed trans- fatty acids have become interesting in early 1970s as nutritionally undesirable. Emerging data suggest that trans-fatty acids may raise blood levels of low-density lipoprotein (LDL) to much the same extent as saturated fatty acids. In addition, recent studies indicate that trans-fatty acids intake is associated with incidence of heart disease, and that the type, not the amount, of fat in the diet contributes to the risk of this disease $e^{4,5}$.

A particulary important group of compounds within unsaturated fatty acids are the long-chain $\left(\mathrm{C}_{16}\right.$ to $\left.\mathrm{C}_{20}\right)$, polyunsaturated fatty acids (PUFAs). Humans can synthesize certain fatty acids, however, a body is unable to desaturate long-chain fatty acids at either $\mathrm{C}_{3}$ or $\mathrm{C}_{6}$ from the methyl end, but can at $\mathrm{C}_{9}$. For this reason n-3 and n-6 PUFAs have been termed "essential fatty acids (EFAs)". In all cases, the suffixes n-3, n-6 and n-9 show 
that the position of the first double bond is located three, six or nine carbon atom away from the last methyl group.(Sometime, $\omega-3, \omega-6$ or $\omega-9$ suffix is used instead of n-, as omega is the last greek letter). Fatty acid biosynthetic pathways are depicted on Figure 1.

$\alpha$-Linolenic acid (LNA) and linoleic acid (LA) are two basic members of the $n-3$ series and $n-6$ of PUFAs as well as oleic acid is the basic member of the $n-9$ serie of unsaturated fatty acids. Oleic acid (OA) can be elongated and desaturated by the same enzymes to produce so called mead acid (5,8,11-eicosatrienoic acid) but is not a precursor for eicosanoids. This compound does indicate essential fatty acid deficiency when present, because it is only formed when there is insufficient LNA or LA for elongation and desaturation.

These three series of fatty acids have numerous interrelationships with considerable clinical impact. Over thousands of years of an agriculture based existence, the dietary ratio n-3:n-6 remained stable at about 1 . However, in the past 100 years changes in the food supply and dietary habits have caused this ratio to fall dramatically to less than 0.1 . Within a range of total caloric intake of 2000-2500 Kcal, a proper safety ratio of OA : LA : LNA could be expressed as 11-16:4-6:1. Recent data show that diet including about $13 \%$ of OA in the total caloric intake could protect from the occurrence of new cardiovascular events, but increase of OA intake to more than $20 \%$ could limit this beneficial intake by inducing an increase of low-density lipoprotein in blood.

Interest in possible health benefits of the n-3 PUFAs, was originally stimulated by epidemiological observations of Greenland Eskimos ${ }^{6}$. Fatty acids from marine lipids have been shown to have beneficial effects on the cardiovascular system ${ }^{7}$ and to have antiinflammatory properties ${ }^{8,9}$ which are attributed mainly to the ability to modify prostaglandin and lipid synthesis. Human beings evolved on a diet that was lower in total fat and saturated fat, but contained almost equal amounts $n-6$ and n-3 PUFAs. Today this ratio is about $10-20: 1$, indicating deficient in n-3 PUFAs compared with the diet on which humans evolved and their genetic patterns were established. The n-3 and n- 6 fatty acids are not interconvertible in the human body, and therefore, appropriate amounts of both acids need to be considered in making dietary recommendations. The food industry is already taking steps to return n-3 PUFAs to the food supply by enriching various products with safety sources of n-3 fatty acids ${ }^{10}$. They are obtained by humans primarily from fish oils and fish products.

The richest vegetable source of the n-3 PUFAs serie, represented by LNA seems to be flax oil (Linum usitatissimum), perilla oil (Perilla frutescens) and dragonhead oil (Dracocephalum moldavica). Comparison of the fatty

\section{FATTY ACID BIOSYNTHESIS PATHWAYS}
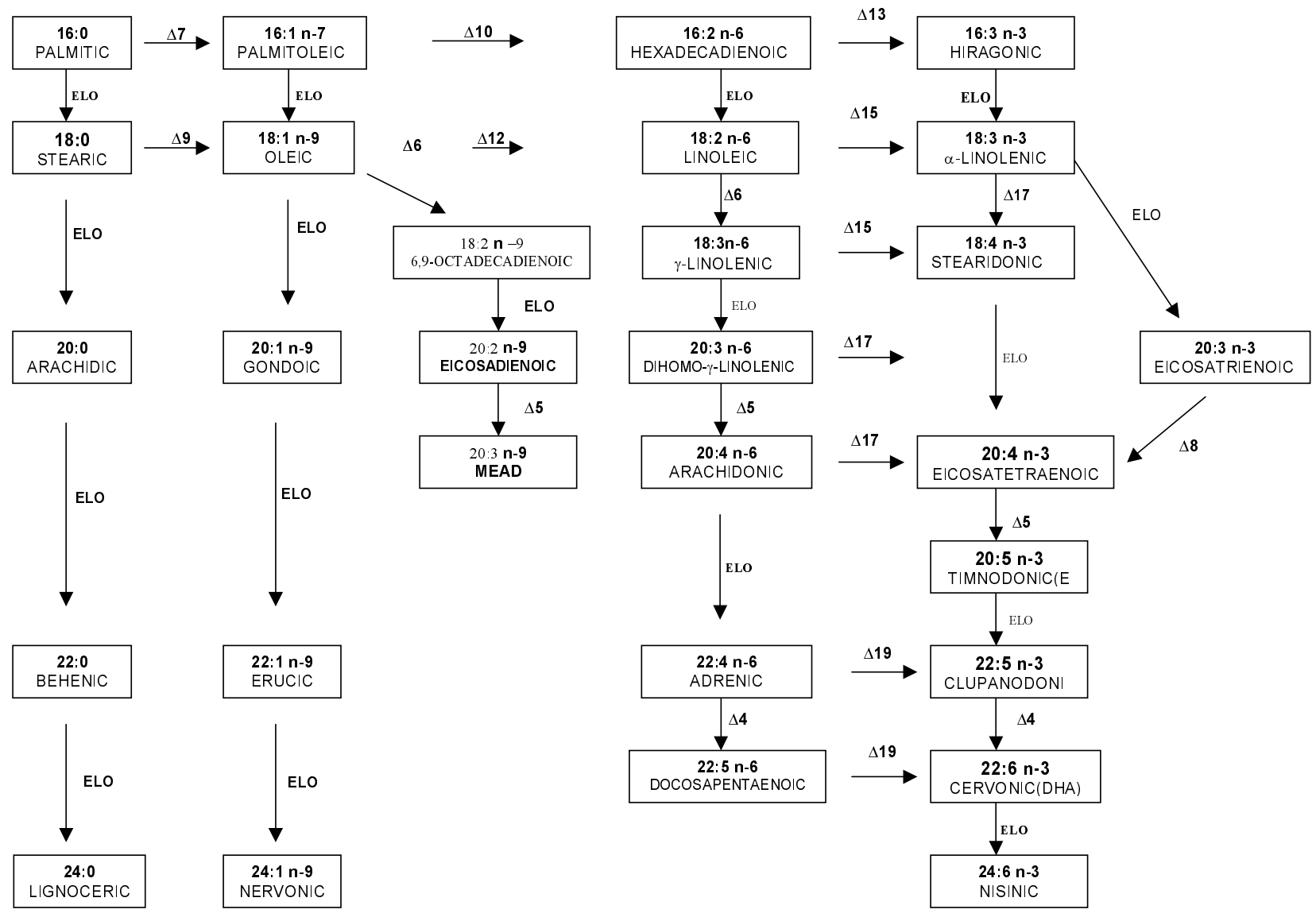
acids composition according to individual families representation and quantity of oil in seeds is depicted in Tables 1-3. The seed of some flax strains also contain cyanogenic glycosides which stimulate respiration and improve digestion, but if in excess, they can cause respirature failure. An edible oil obtained from these seeds must be properly refined. Perilla oils come from a plant of common name Shiso (also called Beefsteak plant) which has been consumed in the East Asia for houndred of years. The plant Moldovian Dragonhead is particularly used for its content of essential oil in all above ground parts, however the seeds with about $15 \%$ of vegetable oil contain more than $60 \%$ of LNA.

Vegetable LNA thus serves as the precursor of higher member of the n-3 serie of fatty acids well known from fish oils. For example, LNA can be converted in man to eicosapentaenoic acid (EPA) or docosahexaenoic acid (DHA) but with a limited efficiency ${ }^{11}$.

Viper's Bugloss (Echium plantagineum) seed oil is the first commercially produced oil containing both substantial amounts of n-3 fatty acids represented by $\alpha$-LNA (27-40\%), stearidonic acid (8-14\%) and n-6 fatty acids represented by LA (17-28\%) with $\gamma$-LNA (7-12\%). Numerous clinical surveys have indicated that intake of well balanced n-3/n- 6 fatty acids may be beneficial in alleviating the pain, progressing of arthritis and in suppressing excessive inflamatory responses.

As the available arable land a freshwater decrease in some countries, the search for wild, salt tolerated plants (halophytes) becomes more urgent. Over the past 20 years, the halophyte Salicornia bigelovii has been domesticated into a new edible oilseed crop with seawater irrigation. The seeds of of improved salicornia strains (with a marginal content of saponins in seed) contain high level of oil (about $30 \%$ ) which is exceptional in containing LA as high as that in safflower oil.This oil has a pleasant, nutty flavour and can be extracted from the seed and refined using conventional equipment. Through the breeding improvement and the development of seawater irrigation technology, salicornia has been successfully cultivated in Mexico, India, Eritrea, Saudi Arabia and the United Arab Emirates.

$\gamma$-Linoleic acid (GLA) is the immediate 6-desaturated metabolite of linoleic acid,the main dietary PUFAs. Evening primrose oil (Oenotera biennis) seems be a particularly desirable source of GLA. Some other oils,notably those from starflower (Borago officinalis) or blackcurrant (Rybis nigrum) contain substantially higher amounts of GLA. However, in spite of their higher GLA content, they are less clinically effective than evening primrose oil ${ }^{12,13}$. The relative efficacies of different oils containing GLA depend on its glyceride structures $^{14}$. GLA have a trophic effect on the small intestine ${ }^{15}$ and is involved in the protective mechanisms of the stomach against ulceration ${ }^{16}$. In our part of the world, to most people Hemp plant (Cannabis sativa) is synonymous with marijuana. Nutritionaly oriented experts are working to educate people about the immense potential of this plant and reintroduce it into the commerce. Hemp seeds contain about $40 \%$ oil with quite few of GLA (approx. $2 \%$ ) which is absent in the oils we normally eat.

Dietary supplementation of very long chain (C 22-24) monoenoic fatty acids such as erucic acid and nervonic acid may be beneficial to individuals with peroxisomal disorders including Zelweger syndrome, multiple sclerosis and adenoleukodystrophy ${ }^{17,18}$. This important FA plays a part in the biosynthesis of myelin and is found in sphingolipids of white matter in the human brain ${ }^{19}$. Nervonic acid is unusual in plant seed oils. The oil from the seeds of plant Honesty (Lunaria annua) is rich by FA of the n-9 series, in particular erucic acid (over $45 \%$ ) and nervonic acid (up to $25 \%$ ). Nervonic acid and its derivatives can be produced from lunaria oil by conventional techniques and easily incorporated into food compositions such as maternal dietary supplements or infant formulae. It is of interest to note that human breast milk contains nervonic acid regularly. Products containing honesty oil and intended for premature birth babies are under active investigation.

In a series of investigations it was observed that the cytotoxic action of anticancer drugs can be augmented by PUFAs of both $n-3$ and $n-6 \operatorname{series}^{20}$ (GLA, arachidonic acid, EPA and DHA). In addition, these fatty acids could also enhance the cellular uptake of anticancer drugs by tumor cells and thus, are able to potentiate the anti-cancer actions of these drugs. PUFAs can not only kill the tumor cells but can also serve as sensitizing agents rendering various tumor cells responsive to the cytotoxic action of various anti-cancer drugs and lymphokines such as tumor necrosis factor ${ }^{21,22}$. Polyunsaturated fatty acids can selectively kill the tumor cells and can actually behave as anti-angiogenic substance ${ }^{23}$. The physiological efficacy of the native oils likewise cannot simply be related to their content of EFAs. The precise triglyceride structure of the oil, rather than simply amount of EFAs it contains, may be of major importance ${ }^{24,25}$.

Some studies have shown that not only PUFAs can be exploited as possible anti-cancer agents but also conjugated linoleic acids (CLA) and conjugated linolenic acids (CLNA) can be used. CLA have attracted much attention because of their wide-ranging biological effects such as inhibiting tumor growth ${ }^{26,27}$, reducing body fat ${ }^{28}$ and reducing atherosclerotic risk $^{29}$ and modulation of the immune system ${ }^{30}$. Since CLA are mainly of animal origin $^{31}$ as can be seen from Table 4, CLA isomers could also be produced by alkali isomerisation of vegetable oils, which are rich in LA e.g. from tobaco seeds, safflower seeds and milk thistle seeds. These derivatives are found predominantly in the form of triglycerides in beef and dairy products and are synthesized by bacteria in the rumen of the source animals.

CLA can have the two double bonds mainly in the 9 and 11 or in the 10 and 12 positions resulting in eight possible geometric isomers. The $9(\mathrm{Z}), 11(\mathrm{E})$-octadecadienoic acid, so-called rumenic acid, and $10(\mathrm{E})$, 
Table 1. Composition of the oils rich in n-9 fatty acids

\begin{tabular}{|l|c|c|c|c|}
\hline Vegetable oil & $\begin{array}{c}\text { Oil content in seed } \\
{[\mathbf{g} / \mathbf{1 0 0} \mathbf{g}]}\end{array}$ & $\begin{array}{c}\mathbf{C}_{\mathbf{1 8 : 0}} \\
{[\mathbf{\%}]}\end{array}$ & $\begin{array}{c}\mathbf{C}_{\mathbf{1 8 : 1}}(\mathbf{n}-\mathbf{9}) \\
{[\mathbf{\%}]}\end{array}$ & $\begin{array}{c}\mathbf{C}_{\mathbf{1 8 : 2}}(\mathbf{n}-\mathbf{6}) \\
{[\mathbf{\%}]}\end{array}$ \\
\hline Almond & 54 & 5 & $\mathbf{7 8}$ & 17 \\
\hline Olive & 20 & 16 & $\mathbf{7 5}$ & 8 \\
\hline Macadamia & 70 & 12 & $\mathbf{7 1}$ & 10 \\
\hline Avocado & 12 & 20 & $\mathbf{7 0}$ & 10 \\
\hline Hickory & 69 & 9 & $\mathbf{6 8}$ & 17 \\
\hline Pistachio & 54 & 9 & $\mathbf{6 5}$ & 19 \\
\hline
\end{tabular}

Table 2. Composition of the oils rich in n-6 fatty acids

\begin{tabular}{|l|c|c|c|c|}
\hline Vegetable oil & $\begin{array}{c}\text { Oil content in seed } \\
{[\mathbf{g} / \mathbf{1 0 0} \mathbf{g}]}\end{array}$ & $\begin{array}{c}\mathbf{C}_{18: 0} \\
{[\mathbf{\%}]}\end{array}$ & $\begin{array}{c}\mathbf{C}_{18: 1}(\mathbf{n}-9) \\
{[\mathbf{\%}]}\end{array}$ & $\begin{array}{c}\mathbf{C}_{\mathbf{1 8 : 2}}(\mathbf{n}-6) \\
{[\%]}\end{array}$ \\
\hline Safflower & 60 & 12 & 13 & $\mathbf{7 5}$ \\
\hline Grape & 20 & 12 & 17 & $\mathbf{7 1}$ \\
\hline Sunflower & 47 & 12 & 23 & $\mathbf{6 5}$ \\
\hline Corn & 4 & 17 & 24 & $\mathbf{5 9}$ \\
\hline Wheat germ & 11 & 18 & 25 & $\mathbf{5 0}$ \\
\hline Milk thistle & 20 & 5 & 22 & 5 \\
\hline
\end{tabular}

Table 3. Composition of the oils rich in n-3 fatty acids

\begin{tabular}{|l|c|c|c|c|}
\hline Vegetable oil & $\begin{array}{c}\text { Oil content in seed } \\
{[\mathbf{g} / \mathbf{1 0 0} \mathbf{g}]}\end{array}$ & $\begin{array}{c}\mathbf{C}_{\mathbf{1 8 : 3}} \mathbf{( \mathbf { n } - 3 )} \\
{[\mathbf{\%}]}\end{array}$ & $\begin{array}{c}\mathbf{C}_{\mathbf{1 8 : 1}}(\mathbf{n}-9) \\
{[\mathbf{\%}]}\end{array}$ & $\begin{array}{c}\mathbf{C}_{\mathbf{1 8 : 2}}(\mathbf{n}-\mathbf{6}) \\
{[\%]}\end{array}$ \\
\hline Draconhead & 20 & $\mathbf{6 1}$ & 10 & 18 \\
\hline Perilla & $31-55$ & $\mathbf{5 5 - 6 5}$ & $6-20$ & $7-14$ \\
\hline Flax & 35 & $\mathbf{5 8}$ & 19 & 14 \\
\hline Chia & 30 & $\mathbf{3 0}$ & - & 40 \\
\hline Kukui & 30 & $\mathbf{2 9}$ & - & 40 \\
\hline Hemp & $\mathbf{2 0}$ & 12 & 60 \\
\hline
\end{tabular}

Table 4. The natural occurence of CLA in selected foods $\left(\operatorname{after}^{30}\right)$

\begin{tabular}{|l|c|c|}
\hline Food & Total CLA (mg/g fat) & Rumenic acid (\%) \\
\hline Homogenized milk & 5.5 & 92 \\
\hline Butter & 4.7 & 88 \\
\hline Yogurt & 4.8 & 84 \\
\hline Cheddar cheese & 3.6 & 93 \\
\hline Mozzarella cheese & 4.9 & 95 \\
\hline Colby cheese & 6.1 & 92 \\
\hline Beef (ground), uncooked & 4.3 & 85 \\
\hline Veal, uncooked & 2.7 & 84 \\
\hline Lamb, uncooked & 5.6 & 92 \\
\hline Pork, uncooked & 0.6 & 82 \\
\hline Canola oil & 0.5 & 44 \\
\hline Sunflower oil & 0.4 & 38 \\
\hline Corn oil & 0.2 & 39 \\
\hline
\end{tabular}

Table 5. Relative compositions of policosanols obtained from different sources

\begin{tabular}{|ll|c|c|c|}
\hline Policosanols & & Tall oil & Rice bran wax & Sugarcane wax \\
\hline Eicosanol & $\mathrm{C}_{20}$ & 0.2 & - & - \\
\hline Heneicosanol & $\mathrm{C}_{21}$ & 0.1 & - & - \\
\hline Docosanol & $\mathrm{C}_{22}$ & 50.7 & 1.1 & - \\
\hline Tricosanol & $\mathrm{C}_{23}$ & 2.7 & - & 0.7 \\
\hline Tetracosanol & $\mathrm{C}_{24}$ & 45.7 & 11.6 & - \\
\hline Pentacosanol & $\mathrm{C}_{25}$ & 0.3 & - & 8.0 \\
\hline Hexacosanol & $\mathrm{C}_{26}$ & 1.0 & 10.6 & 3.5 \\
\hline Heptacosanol & $\mathrm{C}_{27}$ & - & - & 66.0 \\
\hline Octacosanol & $\mathrm{C}_{28}$ & - & 20.2 & 0.8 \\
\hline Nonacosanol & $\mathrm{C}_{29}$ & - & - & 13.5 \\
\hline Triacontanol & $\mathrm{C}_{30}$ & - & 30.1 & 6.0 \\
\hline Dotriacontanol & $\mathrm{C}_{32}$ & - & 16.8 & 1.5 \\
\hline Tetratriacontanol $\mathrm{C}_{34}$ & - & 8.0 & - \\
\hline Haxatriacontanol $\mathrm{C}_{36}$ & - & 1.4 & \\
\hline
\end{tabular}


12(Z)-octadecadienoic acid are predominant isomers and it is thought to be the biologically active form (Figure 2).

When CLA inhibits breast cancer, it may acts in two ways: it directly inhibits growth of mammary epithelial cells by inhibition of DNA synthesis and simulation of cell death, second possibility is that they may have an effect on eicosanoid synthesis. Although most of the physiological activities have been investigated using a mixture of CLA isomers, it was recently reported that $10(\mathrm{E}), 12(\mathrm{Z})$-octadecadienoic acid participates in the decrease of body fat ${ }^{32,33}$ and that $9(\mathrm{Z}), 11(\mathrm{E})$-octadecadienoic acid possesses anticancer activity ${ }^{34}$. It is important to realise that many of these physiological effects have been demonstrated only in animal experiment, and have yet to be tested on human subjects.

\section{FATTY ALCOHOLS}

Two groups of vegetable raw materials are used for the production of fatty alcohols:

- wax esters, from which the fatty alcohols are obtained by simple hydrolysis;

- oils, which contain fatty acids in the form of triglycerides that can be hydrogenated after suitable pretreatment to yield fatty alcohols.

Policosanols are a family of aliphatic alcohols found in some vegetable waxes and they affect cholesterol biosynthesis in the liver. Overall cholesterol reduction ranges from $15-20 \% 3$. In addition, the policosanols (namely C28-30) inhibits abnormal platelet aggregation, reduce complication in people with coronary heart disease and increases endurance during exercise. Long term use of policosanols may reduce the body's biosynthesis of the ubidecarone and so, some formulations are fortified by coenzyme Q 10 . Policosanols from 20 to 26 carbon atoms can be obtained from the neutral fraction of the tall oil. Other sources such as sugarcane wax, rice bran wax provide range policosanols from 24 to 36 carbon atoms. Sugarcane wax which occurs on the surface of sugarcane leaves and stolles (Saccharum officinarum) is obtainable from the sludges of cane-juice processing. The wax content of rice bran oil (Oryza sativum) can be somewhat variable, depending upon cultivar and processing parameters. Relative compositions of policosanols obtained from different sources ${ }^{36}$ is stated in Table 5.

\section{ISOPRENOIDS}

Isoprenoids constitute a diverse class of lipids accompanying compounds constructed from a repeating isoprene unit. Isoprenoids may be divided into three distinct structural classes:

- terpenes, linear mono-,sesqui-, di-,tri-,tetra-isoprene polymers (e.g. carotenoids,squalene),
- steroids, complex four-membered ring structures derived from triterpenes (e.g. phytosterols),

- mixed isoprenoids are terpenes linked to non-terpene molecules (e.g. tocopherols, tocotrienols).

Terpenes function as antioxidants, protecting lipids, blood and other body fluids against attack by free radicals, some type of reactive oxygen, hydroxylic groups, peroxides and superoxide radicals. This group has an abundant distribution in vegetables, leafes, greens, soy products and grains. The most widely studied terpenes are squalene and carotenoids. Other well known substances requiring isoprene groups for their biosynthesis include ubiquinone and vitamins A, D, E and K.

Squalene is a symmetrical hydrocarbon containing six isoprene units primarily known for its key role as intermediate metabolite in the plant sterol biosynthesis.It received its name because of its occurence in shark (Squalus) liver oil. However, it is widely distributed in plants, with reasonable amounts found in amaranth oil (Amarathus cruentus or Amaranthus hypochondriacus), olive oil ,wheat germ oil and rice bran oil. In humans, about $60 \%$ of dietary squalene is absorbed. It is transported in serum generally in assotiation with wery low density lipoproteins and is distributed with the greatest concentration in the skin, wherw it is one of the major components of skin surface lipids. Squalene appears to function in the skin as a quencher of singlet oxygen, protection human skin surface from lipid peroxidation due to expose to UV radiation ${ }^{37}$. The primary use of squalene currently is as an adjunctive therapy in a variety of cancers ${ }^{38,39}$. In animals, supplementation of the diet with squalene can reduce cholesterol and triglyceride levels ${ }^{40}$. However, two humans reports indicate no change in cholesterol absorption while supplementing the diet with squalene ${ }^{41,42}$.

Carotenoids, this subclass of tetraterpenes have positive effects on immunological system and protect the skin from ultraviolet radiation ${ }^{43,44}$. Lycopene is the carotenoid which is found in the highest concentration in human plasma could reduce the risk of prostate cancer ${ }^{45}$.

\section{Triterpenoids and Phytosterols}

Phytosterols are minor constituents of vegetable oils present in the unsaponifiable fraction. This fraction with a complex composition constitutes in average 0.3 to $2 \%$ of the oil, but it can reach more than $10 \%$ in certain plants such as Amaranthus or Butyrospermum parkii. The most common phytosterols in nature are namely $\beta$-sitosterols, campesterol and stigmasterol. Composition of phytosterols in all pharmacopoeial seed oils have been tabled in review ${ }^{46}$. Plant sterols fall into one of three categories:

4-desmethylsterols (no methyl group),

4-monomethylsterols (one methyl group) and

4,4-dimethylsterols (two methyl groups).

They occur in the free form but also esterified to free fatty acid, fenolic acid or sugar moieties. Plant stanols are saturated counterparts of the plant sterols 
and lack the carbon-carbon double bonds found in phytosterols. The phytostanols are less abundant in nature than corresponding phytosterols, they can easily be made by hydrogenation methods. Consequently, the average dietary intake of phytostanols, in Western diets, is roughly one tenth of consumed phytosterol amount $\sim 250 \mathrm{mg} / \mathrm{day}^{47}$. The estimated daily phytosterol content in the vegetarian diet is about $500 \mathrm{mg} / \mathrm{day}^{48}$. Traditionally, phytosterols have been isolated from sources as corn oil, wheat germ oil or rapae oil. Phytosterol in monograph according European Pharmacopoeia 4-th ed., suppl. 1 is defined as natural mixture of at least $70 \%$ $\beta$-sitosterol with other sterols, obtained from plants of the genuses Hypoxis, Pinus and Picea. Phytosterol content from unsaponifiable matter of some non pharmacopoeial vegetable oils is listed in Table 6.

Phytosterols are not syntesized in human body. Their intestinal absorption is less than $5 \%$ of dietary levels and plasma levels are generally less than $1 \%$ of cholesterol levels. Absorbed phytosterols are efficiently cleared from the circulation via biliary route. Their poor absorption is not fully understood. One proposed explanation is that phytosterols may be inadequately esterified in the intestine. Research data has also sugested that some phytosterols are not absorbed at the proximum jejunum at all (sitostanol) and, when there is absorption ( $\beta$-sitosterol), it is in very limited quantities. It appears to involve the inhibition of cholesterol absorption from the proximum jejunum by competing with cholesterol at specific uptake sites.

The cholesterol lowering effects of phytosterols and phytostanol fatty acid esters have been the subjects of various studies. A great number of studies with phytosterol intakes up to $25 \mathrm{~g}$ /day for several months have been performed without reporting side effects. Only patients with sitosterolemia, a rare inherited lipid storage disease leading to premature atherosclerosis, have a very high absorption rate of phytosterols and show serious side effects ${ }^{49}$. Until recently, it was commonly thought that stanols were superior to sterols in lowering serum cholesterol levels. The oral administration of phytosterols is complicated by their tendency to be unpalatable and nauseating. Therefore, the products containing phytosterols are often not organolepticaly pleasing in structure and mouth-feel. Plant sterols, like lipids in generaly are sensitive to oxidation in the presence of air. Since cholesterol oxidation products are recognized as harmful compounds, it is important to study what kinds of products are formed from phytosterols that are frequevently used as functional foods. The major thermooxidation products of phytosterols are 7-hydroxy, 7-keto and 5,6-epoxy compounds of sitosterol and campesterol. Biological activities of some steryl glycosides (also known as phytosterolins) have been investigated such as their effects on complement activation and their anti-inflamatory activity . Majority of this work has been carried out with (-sitosterol glucoside and its aglycone. Phytosterols and phytosterolins modulate the functions of T-cells,B-cells and NK-cells to such extent that immune homeostasis and normalization of a defective immune system could ensue following the intake of phytosterols and phytosterolins ${ }^{50}$.

\section{Mixed isoprenoids}

Plants and their oils are the best sources of different compounds, belonging to the vitamin E family. The proposed term tocopherols was used to name the initial four compounds designated as alpha-, beta-, gammaand delta-tocopherol. Their structures have two primary parts, a complex chroman ring and a long saturated side chain. Tocotrienols have an unsaturated isoprenoid side chain which allows to function in a uniquely different manner than tocopherols. Tocopherols are most common in the diet than tocotrienols ${ }^{51}$. While tocopherols are predominantly found in maize, soybean and olive oils, tocotrienols are found at relatively high concentrations in oils extracted from the fruit of the palm tree, other sources include rice bran,wheat germ and barley ${ }^{52}$. Palm fruit oil is the only complete source of all four tocotrienol isomers ${ }^{53}$. Tocopherols and tocotrienols are

Table 6. Phytosterols content from unsaponifiable matter of some vegetable oils

\begin{tabular}{|l|c|c|c|c|}
\hline Phytosterols & $\begin{array}{c}\text { Milk Thistle oil } \\
(\%)\end{array}$ & $\begin{array}{c}\text { Amaranth oil } \\
(\%)\end{array}$ & $\begin{array}{c}\text { Dragonhead oil } \\
(\%)\end{array}$ & $\begin{array}{c}\text { Shea butter } \\
(\%)\end{array}$ \\
\hline Cholesterol & 3.81 & & 0.07 & $1-3$ \\
\hline Brassicasterol & & 0.03 & 0.41 & \\
\hline Campesterol & 6.92 & 1.49 & 17.00 & \\
\hline Campestanol & 0.07 & 0.28 & 0.16 & \\
\hline Stigmasterol & 7.83 & 1.55 & 2.49 & \\
\hline$\Delta 7$-Campesterol & 4.24 & 18.37 & 0.70 & \\
\hline Clerosterol & 0.37 & 0.11 & 0.73 & \\
\hline$\beta$-Sitosterol & 35.74 & $31.31 ?$ & 57.81 & \\
\hline$\beta$-Sitostanol & & 0.67 & 0.48 & $38-41$ \\
\hline$\Delta 5$-Avenasterol & 3.74 & 1.82 & 9.48 & $2-6$ \\
\hline$\Delta 5,24-$ Stigmastadienol & 1.06 & 0.87 & 1.26 & $5-6$ \\
\hline$\Delta$ 7-Stigmasterol & 22.55 & 22.69 & 2.03 & \\
\hline$\Delta$-Avenasterol & 3.29 & 10.00 & 0.58 & \\
\hline Isofucosterol & & & & \\
\hline Fucosterol & 1.32 & 2.67 & 1.44 & \\
\hline$\alpha$-Spinasterol & & & & \\
\hline
\end{tabular}


known for their effective inhibiting effect upon the oxidation processes of lipids in foods and in biological systems ${ }^{54}$. In the last few years,tocotrienols have been exlusively studied with particular interest in breast cancer, cardiovascular disease, skin health and aging, their cholesterol-lowering capabilities ${ }^{55,56}$.

\section{CONCLUSION}

Although lipids, namely fats have an unhealthy connation to the public, they are necesary for human growth and health. Lipids perform a variety of functions within the human body, from storing body fats in adipose tissue to providing cell membranes with a structure. Under normal physiological condition more than $95 \%$ of the ingested lipids in the human diet is processed and absorbed. The average daily diet consists of 100-150 g of fats. Various vegetable lipid forms are widely used in specialized nutritional systems designed to manage nutritional disorders including malabsorption and maldigestion syndromes, to facilitate patient recovery from disease or surgery, or to support the special nutritional needs of premature infants, children and the elderly. Development of advanced enteral nutritional products is one field that utilizes specialized lipid systems to enhance nutritional performance. The science behind the effects of dietary fat on human health is so complex that there are no simple and straigthforward answers to gain a broader understanding of the interactions between diet and health. Groving public health and fitness awareness and advances in nutrition research have raised the level of debates on the pros and cons of various dietary lipids and its component.

\section{REFERENCES}

1. Diplock AT, Aggett P, Ashwell M, Bornet F, Fern E, Roberfroid M (1999) Scientific concepts of functional food science in Europe: Consensus document. Brit. J. Nutr. Suppl. 1, 1-28.

2. Southon S (2000) Factors to consider when undertaking clinical trials for functional foods. (1999) In: Functional foods II. Claims and evidence (Buttriss J, Saltmarsh M, eds.), The Royal Society of Chemistry, Cambridge, pp. 3-7.

3. Tsevegsüren N, Aitzetmüller K, Brühl L, Werner G (2000) Seed oil fatty acids of mongolian compositae: The trans-fatty acids of Heteropappus hispidus, Asterothamnus centrali-asiaticus and $\mathrm{Ar}-$ temisia palustris. J. High Resol Chromatogr., 23(5), 360-366.

4. Katan MB, Mensink RP, Zock PL (1995) Trans-fatty acids and their effect on lipoproteins in humans. Annu. Rev. Nutr., 15, 473-493.

5. Mensink RP, Katan MB (1990) Effect of dietary trans fatty acids on high-density and low-density lipoprotein cholesterol levels in healthy subjects. N. Engl. J. Med., 323, 439-445.

6. Bang HO, Dyerberg J, Hjorne N (1976) The composition of foods consumed by Greenland Eskimos. Acta Med. Scand., 200, 67-73.

7. Mc Lennan P, Howe P, Abeywardena M, Muggli R, Raederstorff D, Mano M, Rayner T, Head R (1996) The cardiovascular protective role of docosapentaenoic acid. Eur. J. Pharmacol., 300, (1-2), pp 83-89.

8. Raederstorff D, Pantze M, Bachmann H, Moser U (1996) Antiinflamatory properties of docosahexaenoic and eicosapentaenoic acid in phorbol.ester-induced mouse ear inflamation. Int. Arch. Allergy. Immunol., 111, (3), 284-290.

9. Mancuso P, Whealan J, Demichele SJ, Snider J, Guszca J, Karlstad M (1997) Dietary fish oil and fish and borage oil suppress intrapulmonary proinflamatory eicosanoid biosynthesis and attenuate pulmonary neutrophil accumulation in endotoxic rats. Crit. Care Med., 25, 1196-2006.

10. Simopoulos AP, Leaf A, Salem N Jr. (1999) Essentiality of and recommended dietary intakes for omega- 6 and omega-3 fatty acids. Ann. Nutr. Metab., 43, 127-130.

11. Meydani SN, Lichtenstein A, Cornwall S, Meydani M, Goldin BR, Rasmussen H, Dinarello CA, Schaefer EJ (1993) Immunological effects of National Cholesterol Education Oil Panel Step-2 diets with and without fish-derived a-3 fatty acid enrichment. J. Clin. Invest., 92, 105-113.

12. Jenkins DK, Mitchel JC, Manku MS, Horrobin DF (1988) Effects of different sources of GLA on the formation of essential fatty acid and prostanoid metabolites. Med. Sci. Res., 16, 525-526.

13. Ratnayake WMN, Matthews DG, Ackman RC (1989) Triacylglycerols of evening primrose (Oenothera biennis) seed oil. J. Am. Oil Chem. Soc., 66, 966-969.

14. Muderhwa JM, Dhuique-Mayer C, Pina M (1987) Distribution of fatty acids in the glycerides of gamma-linolenic acid containing oils. Oleagineux, 42, 207-211.

15. Jenkins AP, Thompson RPH (1989) Trophic effect of Efamol on the rat small-intestinal mucosa. Clin. Sci., 77, 555-559.

16. Tarnawski A, Hollander D, Gergely H (1987) Protection of the gastric mucosa by linoleic acid-a nutrient essential fatty acid. Clin. Invest. Med., 10, 132-135.

17. Martinez M (1995) Polyunsaturated fatty acids in the developing brain, erythrocytes and plasma in peroxisomal disease: Therapeutics implications. J. Inherit. Metab. Dis., 18, Suppl. 1, 61-75.

18. Moser AB, Kreitner N, Bezman L, Lu S, Raymond GV, Naidu S, Moser HW (1999) Plasma very long chain fatty acids in 3,000 peroxisome disease patients and 29,000 controls. Ann. Neurol., $45,(1), 100-110$.

19. Sargent J, Coupland K (1994) Application of specialized oils in the nutritional therapy of demyelating disease. Lipid Technology, $6,(1), 10-14$.

20. Simopoulos A (1991) Omega-3 fatty acids in health and disease and in growth and development. Am. J. Clin. Nutr., 54, 438-463.

21. Das UN (1991) Tumoricidal action of cis-unsaturated fatty acids and its relationship to free radical and lipid peroxidation. Cancer Lett., 56, 235-243.

22. Begin ME, Das UN, Els G (1986) Cytotoxic effects of essential fatty acids in mixed cultures of normal and malignant human cells. Prog. Lipid Res., 25, 573-577.

23. Battegay EJ (1995) Angiogenesis: mechanistic insights, neovascular diseases, and therapeutic prospects. J. Mol. Med., 73, 333-346.

24. El Boustani S, Colette C, Monnier L, Descomps B, Crastes De Paulet A, Mendy F (1987) Enteral absorption in man of eicosapentaenoic acid in different chemical forms. Lipids, 22, 711-714.

25. Jenkins DK, Mitchell JC, Manku MS, Horrobin DF (1988) Effects of different sources of gamma-linolenic acid on the formation of essential fatty acid and prostanoid metabolites. Med. Sci Res., 16, 525-526.

26. Ip C, Chin SF, Scimeca JA, Pariza MW (1991) Mammary cancer prevention by conjugated dienoic derivative of linoleic acid. Cancer Res., 51, 6118-6124.

27. Visconeau SA, Cesano SA, Tepper JA, Scimeca JA, Santoli D, Kritchevsky D (1997) Conjugated linoleic acid suppress the growth of human breast adenocarcinoma cells in SCID mice. Anticancer Res., 17, 969-973. 
28. Park Y, Albright KJ, Liu W, Storkson JM, Cook ME, Pariza MW (1997) Effect of conjugated linoleic acid on body composition in mice. Lipids, 32, 853-858.

29. Nicolosi RJ, Rogers EJ, Kritchevski D, Scimeca JA, Huth PJ (1997) Dietary conjugated linoleic acid reduces plasma lipoproteins and early aortic atherosclerosis in hypercholesterolemic hamsters. Artery, 22, 266-277.

30. Belury MA (1995) Conjugated dienoic linoleate: a polyunsaturated fatty acid with unique chemoprotective properties. Nutr. Rev., 53, 83-89.

31. Kritchevski D, Cyarniecki SK (2001) Conjugated linoleic acid CLA in health and disease. Chim. Oggi (Chemistry Today), 19(6), 26-28.

32. Park HS, Ha YL, Park YJH (2001) Dietary conjugated linoleic acid (CLA) induces apoptosis of colonic mucosa in 1,2-dimethylhydrazine-treated rats: A possible mechanism of the anticancerogenic effect by CLA. Br. J. Nutr., 85, 549-555.

33. De Deckere EA, Van Amelsvoort JM, Mc Neil GP, Jones P (1999) Effect of conjugated linoleic acid CLA isomers on lipid levels and peroxisome proliferation in the hamster. Br. J. Nutr. 82, 309-317.

34. Ha YL, Storkson JM, Pariza MV (1990) Inhibition of benzopyrene-induced mouse forestomach neoplasia by cojugated dienoic derivative of linoleic acid. Cancer Res., 50, 1097-1101.

35. Yatcilla M (2002) Policosanols. Nutraceuticals World, 2002, April, 28-34.

36. Schersi EMQ (2001) Compositions containing phytosterol and policosanolsesters of fatty acids for reducing blood cholesterol and triglyceride. European Patent Application EP 1121928 A1, Date of filing 30. 01. 2001.

37. Storm HM, Oh SY, Kimler BF (1993) Radioprotection of mice by dietary squalene. Lipids, 28, 555-559.

38. Newmark HL (1997) Squalene, olive oil, and cancer risk: a review and hypothesis. Cancer Epidemiol. Biomarkers Prev., 6, 1101-1103.

39. Rao CV, Newmark HL, Reddy BS (1998) Chemopreventive effect of squalene on colon cancer. Carcinogenesis, 19, 287-290.

40. Richter E, Schafer SG (1982) The effect of squalene on the absorption of dietary cholesterol by the rat. Res. Exp. Med., 180, 189-191.

41. Strandberg TE, Tilvis RS, Miettinen TA (1990) Metabolic variables of cholesterol during squalene feeding in humans: comparison with cholestyramine treatment. J. Lipid Res., 31, 1637-1643.

42. Miettinen TA, Vanhanen H (1994) Serum concentration and metabolism of cholesterol during rapeseed oil and squalene feeding. Am. J. Clin. Nutr., 59, 356-363.
43. Bendich A (1989) Carotenoids and the immune response. J. Nutr., 119(1), 112-115.

44. Bendich A, Olson JA (1989) Biological action of carotenoids. FASEB J., 3(1), 1927-1932.

45. Stahl WY, Sies H (1996) Lycopene: A biologically important carotenoids for humans? Arch. Biochem. Biophys., 336, 1-9.

46. Stuchlik M, Zak S (2001) Lipid-based vehicle for oral drug delivery. Biomed.Papers, 145(2), 17-26.

47. Hicks KB, Moreau RA (2001) Phytosterols and phytostanols: Functional food cholesterol busters. Food Technology, 55(1), $63-67$.

48. Kutney J, Milanova R, Chen H, Stoynov NM (2000) Novel glycosides comprising pentose mono-, di-, tri-, or oligosacharides and phytosterols and/or phytostanols. International Patent Application WO 01/32679 A 2, Date of filing 01. 11. 2000.

49. Van Vliet T, Meijer GW, Westrate JA, Hendriks HFJ (2000) Plant Sterol-enriched Margarines, Efficacy in cholesterol lowering and effects on lipid soluble vitamins. In Functional Foods II, Claims and Evidence. Ed. Buttriss, J., Saltmarsh, M.: The Royal Society of Chemistry, Thomas Graham House, Cambridge.

50. Bouic PJD, Albrecht CF (1992) Compositions of phytosterols and phytosterolins as immunomodulators. European Patent Application 0509656 A1,Date of filing 25. 03. 1992.

51. Theriault A, Chao J-T, Wang Q, Gapor A, Adeli K (1999) Tocotrienols: A rewiev of its therapeutic potential. Clin. Biochem., 32 (5), 309-319.

52. Qureshi A, Salzer S, Parmer R, Emerson EE (2001) Novel tocotrienols of rice bran inhibit atherosclerotic lesion in $\mathrm{C} 57 \mathrm{BL} / 6$ apoE-deficient mice. J. Nutr., 131, 2606-2618.

53. Packer L,Weber S, Rimbach G (2001) Molecular aspects of alpha-Tocotrienol antioxidant action and cell signaling. J. Nutr., 131, 369-373.

54. Burton GW, Traber MG (1990) Vitamin E. Antioxidant activity, biokinetics and bioavailability. Amer. Rev. Nutr., 10, 357-382.

55. Goh SH, Hew NH, Norhanom AW, Yadav M (1994) Inhibition of tumor promotion by various palm-oil tocotrienols. Int. J. Cancer, 57, 529-531.

56. Suarna C, Hood RL, Dean RT, Stocker R (1993) Comparative antioxidant activity of tocotrienols and other natural lipid-soluble antioxidant in a homogenous system, and in rat and human lipoproteins. Biochim. Biophys.Acta, 1166, 163-170. 